\title{
3-6 Yaş Grubu Çocuğa Sahip Annelerin Tamamlayıcı ve Alternatif Tıp Uygulamaları
}

\section{Complementary and Alternative Medicine Applications of Mothers with Children in the 3-6 Age Group}

\author{
Selen Özakar Akça ${ }^{1}$ (D) Zehra Doğan ${ }^{2}$ (iD) Zehra Aydın ${ }^{3}$ (iD) Semra Söngüt ${ }^{4}$ (iD \\ ${ }^{1}$ Hitit Üniversitesi Sağlık Bilimleri Fakültesi, Çocuk Sağlı̆̆ı ve Hastalıkları Hemşireliği Anabilim Dalı, Çorum, TÜRKIYYE \\ ${ }^{2}$ İzmir Katip Çelebi Üniversitesi Sağlık Bilimleri Fakültesi, Çocuk Sağlığı ve Hastalıkları Hemșireliği Anabilim Dalı, İzmir, TÜRKIYE \\ ${ }^{3}$ Hitit Üniversitesi Sağlık Bilimleri Fakültesi, Cerrahi Hastalıkları Hemşireliği Anabilim Dalı, Çorum, TÜRKIYE \\ ${ }^{4}$ Hitit Üniversitesi İskilip Meslek Yüksekokulu, Çorum, TÜRKIYY
}

Geliș tarihi/ Date of receipt: 08/05/2021 Kabul tarihi/ Date of acceptance: 29/06/2021 (c) Ordu University Faculty of Health Sciences, Department of Nursing, Turkey, Published online: 08/09/2021

ÖZ

Amaç: Modern tıp dışındaki tedavi uygulamaları olarak tanımlanan Tamamlayıcı ve Alternatif Tedavi (TAT) uygulamaları, ülkemizde giderek artmaktadır. Bu çalışma, 3-6 yaş grubunda çocuğu olan annelerin TAT uygulamalarını belirlemek amacı ile yapılmıştır.

Yöntem: Bu çalışma tanımlayıcı olarak planlanmıştır. Araştırmanın evrenini bir ilin Milli Eğitim Müdürlüğüne bağlı tüm anaokullarında bulunan 3-6 yaş grubundaki çocukların anneleri $(\mathrm{N}=1003)$, örneklemini ise, araştırmaya dahil edilme kriterlerine uyan ve araştırmaya katılmayı kabul eden 988 anne oluşturmuştur. Çalışmanın verileri, anket formu kullanılarak toplanmıştır. İstatistiksel analizler SPSS paket programı ile yapılmış, tanımlayıcı istatistikler için frekans (\%), ortalama, standart sapma ( \pm SS), minimum-maximum değerleri, grupların karşılaştırılmasında kategorik veriler için ki-kare testleri kullanılmıştır. $\mathrm{p}<0.05$ olması istatistiksel olarak anlamlı kabul edilmiştir.

Bulgular: Annelerin yaş ortalaması $32.23 \pm 5.09$ olup, \%83.2'sinin TAT uyguladıkları belirlenmiştir. Çalışmadaki annelerin 25-35 yaş grubunda olanların \%84.7'sinin, lise mezunu olanların \%86.2'sinin, geniş aile yapısında olanların \%86.5'inin, geliri giderinden düşük olanların \%83.3'ünün ve geliri giderine eşit olanların \%83.2'sinin TAT uyguladıkları saptanmıştır. Araştırmadaki annelerin yaş, eğitim durumu, aile

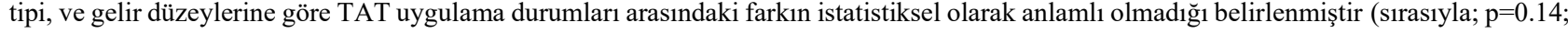
$\mathrm{p}=0.43 ; \mathrm{p}=0.38 ; \mathrm{p}=0.99$ ).

Sonuç: Annelerin TAT uygulama oranları yüksektir. Pediatri hemşirelerinin, TAT uygulamalarının olası riskleri, yararları ve kısıtlamaları hakkında yeterli bilgiye sahip olmaları, bu konuda annelerin bilgilendirilmesi çok önemlidir. Örneklem grubu genişletilerek konu ile ilgili çalışmalar yapılması önerilmekte, TAT uygulamalarının sağlık sistemine etkisinin belirlenmesi için çok merkezli araştırmaların yapılması gerekmektedir.

Anahtar Kelimeler: Tamamlayıcı alternatif tedavi, çocuk, hemşire, anne

\section{ABSTRACT}

Objective: Complementary and Alternative Medicine (CAM) is defined as applications outside of modern medicine and these applications in our country are increasing. This study was carried out to determine CAM applications of mothers with children in the 3-6 age group. Methods: This descriptive study aimed to reach the entire population ( $\mathrm{N}=1003)$, but 988 mothers were admitted to the scope of the research, meeting the inclusion criteria and agreeing to participate in the research. The data were collected using a questionnaire form. Statistical analyzes were performed with SPSS package program. Frequency $(\%)$, mean, standard deviation $( \pm S D)$, minimum-maximum values were used for descriptive statistics and chi-square tests were used for categorical data for comparison of groups. The value of $p<0.05$ was considered statistically significant.

Results: Mean age of the mothers who participated in the study was $32.23 \pm 5.09$, of whom $83.2 \%$ was found to have applied CAM. Mothers applying CAM were determined that $84.7 \%$ were in the $25-35$ age group, $86.2 \%$ were high school graduates, $86.5 \%$ have extended family structure, $83.3 \%$ have lower income and $83.2 \%$ have an income equal to their expenses. . It was determined that the difference between CAM application status and the age, education level, family type and income level of the mothers in the study was not statistically significant ( $\mathrm{p}=0.14 ; \mathrm{p}=0.43 ; \mathrm{p}=0.38 ; \mathrm{p}=0.99$ respectively).

Conclusion: The rate of CAM applications of mothers is high. It is very important that pediatric nurses have sufficient knowledge and fully inform mothers about CAM applications. It is recommended that researchers carry out their studies by expanding the sample group, and multicenter studies should be conducted to determine the impact of the health system of CAM applications.

Keywords: Complementary and alternative medicine, children, nurse, mothers

ORCID IDs of the authors: SÖA: 0000-0002-6943-6713; ZD: 0000-0003-3881-6657; ZA: 0000-0001-5565-1191; SS: 0000-0003-1952-7980

Sorumlu yazar/Corresponding author: Doç. Dr. Selen Özakar Akça

Hitit Üniversitesi, Sağlık Bilimleri Fakültesi, Çocuk Sağlığı ve Hastalıkları Hemşireliği Anabilim Dalı, Çorum, TÜRKIYE

e-posta/e-mail: selenozakar@hotmail.com

*Bu çalışma 15-18 Kasım 2015 tarihinde Ankara'da gerçekleştirilen 5. Ulusal ve 2. Uluslararası Akdeniz Pediatri Hemşireliği Kongresi'nde sözlü bildiri olarak sunulmuştur.

Atıf/Citation: Özakar Akça S, Doğan Z, Aydın Z, Söngüt S. (2021). 3-6 yaş grubu çocuğa sahip annelerin tamamlayıcı ve alternatif tıp uygulamaları. Ordu Üniversitesi Hemşirelik Çalışmaları Dergisi, 4(2), 181-188. DOI:10.38108/ouhcd.934996 


\section{Giriș}

Modern tıp dışındaki tedavi uygulamaları, Tamamlayıc1 ve Alternatif Tedavi (TAT) uygulamaları olarak tanımlanmaktadır. Modern tıbba destek olarak hastanın rahatlaması ve psikolojisinin düzelmesi, bağışıklık sisteminin güçlenmesi, vb. hedeflerle uygulanan tedavi yöntemleri "tamamlayıcı tedavi", modern tıbbın yerine tercih edilen geleneksel tedavi uygulamaları ise "alternatif tedavi" olarak belirtilmektedir (Paknejad ve ark., 2019; Wopker ve ark., 2020). TAT uygulamalarının zararsız ve doğal olduğu düşüncesi, kolay kullanılması, erişiminin kolay olması, ucuz olması ve invaziv girişim gerektirmemesi nedeniyle yaygin olarak kullanılmaktadır (Ceyhan ve Yiğit Taşya, 2016; Çarman ve ark., 2018). TAT uygulamalarının modern tıp yerine tercih edilme nedenleri arasında ise; insanların sağlık hizmetlerini yetersiz görmesi, bilimsel gerçeklere inanmaması, sosyokültürel özelikleri, önyargıları, dini inanışları, ilaçların yan etkilerinden korkması, alternatif tıbba inanması, immün sistemi güçlendirmesi vb. yer almaktadır (Büyük ve ark., 2014; Ceyhan ve Yiğit Taşya, 2016; Choi ve ark., 2019).

TAT uygulamaları Amerika'da Ulusal Sağlık Enstitüsü'ne bağlı Ulusal Tamamlayıcı ve Alternatif Tip Merkezi (National Center of Complementary and Alternative Medicine [NCCAM]) tarafindan standart sinıflama sistemlerinin oluşturulması için beş kategoriye ayrılmıştır. $\mathrm{Bu}$ beş kategoride; alternatif medikal sistem, zihinsel-bedensel uygulamalar, biyolojik bazlı tedaviler, manipülatif ve vücut bazlı tedaviler, enerji tedavileri yer almaktadır ( $\mathrm{Ng}$ ve Mohiuddin, 2020; NCCIH, 2019). Türkiye'de ise T.C. Sağlık Bakanlığı, Geleneksel ve Tamamlayıcı T1p Uygulamaları Yönetmeliği'ni 27 Ekim 2014 tarihli resmî gazetede yayımlamıştır (Resmi Gazete, 2014). Fakat Türkiye'de henüz TAT ürünlerinin kalitesi için standartlar bulunmamaktadır (Bulut Kobya ve Bektaş, 2019).

TAT uygulamaları dünyada ve ülkemizde giderek artmaktadır (Choi ve ark., 2019; Bulut Kobya ve Bektaş, 2019; Ng ve Mohiuddin, 2020). Yapılan çalışmalarda, dünyada çocuklarda TAT uygulamalarının \%11-89 arasında değiştiği bildirilmektedir (Zuzak ve ark., 2013). Türkiye'de ise TAT uygulamasına yönelik birçok çalışma olmakla birlikte (Bulut Kobya ve Bektaş, 2019; Ceyhan ve Yiğit Taşya, 2016; Çarman ve ark., 2018) TAT uygulamasına yönelik genel çocuk popülasyonunda yapılan çalışmaların sınırlı olduğu belirlenmiştir (Taşar ve ark., 2011; Tuncel ve ark., 2014). Türkiye'de TAT uygulamaları ile ilgili araştırmaların yetersiz olması, hastaların kullandığı yöntemler hakkında yanlış bilgi vermesi ve kullandığı uygulamaları gizlemesi nedeniyle TAT uygulama oranları net olarak bilinmemekte, ancak yaygın kullanıldığ 1 ve kullanımın arttığ1 tahmin edilmektedir (Bulut Kobya ve Bektaş, 2019; Çarman ve ark., 2018).

Çocukların tedavisinde TAT uygulamalarının artması sonucu tedavilere bağlı yan etkilerde de artış görülmektedir. TAT uygulamalarının yarar-zarar değerlendirmesinin yapılamaması, TAT ile ilgili bilginin eksik olması, TAT ürünlerinin kontrolünün yeterince gerçekleştirilememesi, bu ürünlerin yanlış adlandırılması ve konu ile ilgili yapılan çalışmaların kisitlı olması vb. nedenlerle yan etkiler gelişebilmektedir (Bulut Kobya ve Bektaş, 2019; Çarman ve ark., 2018; McClafferty ve ark., 2017; $\mathrm{Ng}$ ve Mohiuddin, 2020). Bu doğrultuda pediatri hemşirelerinin holistik bakım anlayışıyla TAT uygulamaları ile ilgili bilgilerini artırmaları gündeme gelmektedir. Amerikan Pediatri Akademisi, çocuklarda TAT uygulamalarının arttığ 1 ve bu nedenle sağlık profesyonellerinin ailelere TAT uygulamaları ile ilgili bilgilendirme yapmaları gerektiğini belirtmektedir (Kemper ve ark., 2008). $\mathrm{Bu}$ nedenle, pediatri hemşireleri, çalıştığ kullanılan TAT uygulamalarını ve bu uygulamaların çocuklardaki etkilerini bilmesi gerekmektedir (Ho ve ark., 2019; Tuncel ve ark., 2014). Ayrica pediatri hemşireleri çocuk ve ebeveynleri ile iletişime geçerek, ön yargısız bir yaklaşım sergileyerek TAT uygulamaları ile ilgili çocuk ve ailelerini değerlendirmeleri, TAT uygulamaları ile ilgili danışmanlık hizmeti vermeleri, kanıt temelli bilgi sunmaları, olumlu uygulamaları desteklemeleri ve olumsuz bilgileri değiştirmeleri bakımın kalitesi yönünden önem arz etmektedir (Aguilar, 2017; Anheyer ve ark., 2018).

Eldeki bilgiler 1 şığında çocuk popülasyonunda TAT uygulamalarının giderek arttığı göz önüne alındığında genel çocuk popülasyonunda yapılan çalışmaların sınırlı olduğu görüldüğünden, Türkiye'de kronik hastalığ1 olmayan/sağl1klı çocuklarda TAT uygulamalarına yönelik araştırmalara daha fazla gereksinim duyulmaktadır. $\mathrm{Bu}$ doğrultuda bu çalışma ile 3-6 yaş grubunda çocuğu olan annelerin TAT uygulamalarının, uygulama/ uygulamama nedenlerinin belirlenmesi ve annelerin yaş, eğitim durumu, aile tipi ve aile gelir düzeylerine göre TAT yöntemlerini uygulama durumlarının karşılaştırılması amaçlanmıştır. 


\section{Yöntem}

\section{Araştırmanın Tipi}

$\mathrm{Bu}$ araştırma tanımlayıcı tiptedir.

\section{Araştırmanın Evreni ve Örneklemi}

Bir ilin Milli Eğitim Müdürlüğüne bağlı tüm anaokullarında bulunan 3-6 yaş grubundaki çocukların anneleri araştırmanın evrenini oluşturmuştur $\quad(\mathrm{N}=1003)$. Çalışmada evrenin tamamına ulaşılması hedeflendiğinden örneklem seçimine gidilmemiştir. Çalışmanın yapıldı̆̆ tarihler arasinda (Mart-Mayis 2015) anaokuluna devam eden çocuğa sahip, araştırmaya katılmayı kabul eden, ulaşılabilen, okuma yazması olan, bilinen kronik bir sorunu olmayan ve iletişimi engelleyecek bir problemi bulunmayan 3-6 yaş grubundaki tüm çocukların ( $\mathrm{n}=988)$ anneleri araştırmanın örneklemini oluşturmuştur. Araştırmaya katılmaya gönüllü olmayan ( 7 anne), kronik hastalıklı çocuğu olan (3 anne) ve anketin ön uygulamasında bulunan (5 anne) 15 anne çalışma kapsamına alınmamış olup 988 anne ile çalışma tamamlanmıştır. Araştırmada evrenin \%98.5'ine ulaşılmıştır.

\section{Veri Toplama Araçları}

Çalışmanın verileri, literatür doğrultusunda (Bulut Kobya ve Bektaş, 2019; Choi ve ark., 2019; Ng ve Mohiuddin, 2020; Paknejad ve ark., 2019; Wopker ve ark., 2020; Zhang ve Hu, 2016) araştırmacılar tarafindan geliştirilen anket formu kullanılarak elde edilmiştir. İki bölümden oluşan anket formunun birinci bölümünde annelerin yaşı, eğitim durumu, vb tanımlayıc1 özelliklerini belirlemeye yönelik sorular, ikinci bölümünde ise annelerin TAT uygulamalarını belirlemeye yönelik sorular (TAT uygulayıp uygulamadıkları, uygulama zamanları, uygulama nedenleri vb.) yer almaktadır. Araştırmanın verileri, yüz yüze görüşme yöntemi ile toplanmıştır. Anneler, hafta içi her gün saat 16.0017.00 arası çocuklarını okula almaya gelmektedir. Araştırmacı tarafından çocuklarını okula almaya gelen annelere, okullarin bekleme salonunda araştırmanın amacı ile ilgili bilgilendirmeler yapılmış, araştırmaya katılmayı kabul edenlere anket formları dağıtılmış ve anketleri ortalama 1015 dakika sürede doldurmaları sağlanmıştır. Araştırma verileri 30 günde toplanmıştır.

Araştırma için hazırlanan anket formunun anlaşılabilirliğinin ve uygulama süresinin belirlenmesi amacıyla, çalışmaya dahil edilme kriterlerine uyan 5 anneye pilot uygulama yapılmış olup, veri toplama formları üzerinde değişiklik yapılmasına ihtiyaç duyulmamıştır. Pilot uygulamada toplanan veriler araştırmaya dahil edilmemiştir.

\section{Verilerin Değerlendirilmesi}

Veriler, SPSS (Version 22.0, SPSS Inc., Chicago, IL, USA) paket programı ile analiz edilmiştir. Verilerin analizinde tanımlayıcı istatistikler için frekans (\%), ortalama, standart sapma $( \pm \mathrm{SS})$, minimum (min.) - maximum (max.) değerleri, grupların karşılaştırılmasında kategorik veriler için ki-kare testleri kullanılmıştır. $\mathrm{p}<0.05$ olması istatistiksel olarak anlamlı kabul edilmiştir.

\section{Bulgular}

Araştırmadaki annelerin yaş ortalaması $32.23 \pm$ 5.09 (min. $=22$, max. $=51)$ olup, annelerin $\% 43.3$ 'ü $(\mathrm{n}=428)$ ilköğretim, \%31.6's1 $(\mathrm{n}=312)$ lise, \%23.1'i $(\mathrm{n}=228)$ üniversite mezunudur. Çalışmadaki annelerin \%79.3'ü çekirdek aile $(n=783), \% 17.3$ 'ü geniş aile $(\mathrm{n}=171)$ yapısındadır ve annelerin çoğunluğunun $(\% 68.8 ; \mathrm{n}=680)$ gelirinin giderine eșit olduğu belirlenmiştir.

Araştırmadaki annelerin, \%83.2'sinin TAT uyguladıkları belirlenmiştir. Annelerin \%61.4'ünün doktora gittikten sonra TAT uyguladığı ve \%91.7'sinin tıbbi tedavi ile birlikte uyguladığı, \%61.5'inin TAT uygulamasindan "kismen fayda gördüğünü” ifade ettiği saptanmıştır. Araştırmadaki anneler TAT uygulama nedeni olarak \%94.8'i medikal tedavinin pahalı olmasını, \%86.8'i medikal tedavinin başarısız olmasını belirtmiştir. Araştırmadaki annelerin \%60.9'unun öksürükte, \%53.2'sinin gripte, \%44.0'ının bağışıklığın güçlendirilmesinde TAT uyguladıkları saptanmıştır (Tablo 1).

Tablo 1. 3-6 yaş grubu çocuğa sahip annelerin TAT uygulama özellikleri $(\mathrm{n}=988)$

\begin{tabular}{lcc}
\hline TAT & n & \% \\
\hline Uygulama durumu (n=988) & & \\
\hline Uygulayan & 822 & 83.2 \\
Uygulamayan & 166 & 16.8 \\
\hline Uygulama zamanı (n=822) & & \\
\hline Doktora gelmeden önce & 318 & 38.6 \\
Doktora geldikten sonra & 504 & 61.4 \\
\hline Uygulama şekli (n=822) & & \\
\hline Tibbi tedavi ile birlikte & 754 & 91.7 \\
Tibbi tedaviyi keserek & 68 & 8.3 \\
\hline Fayda görme durumu (n=822) & & \\
\hline Tam olarak fayda görme & 197 & 19.9 \\
Kısmen fayda görme & 608 & 61.5 \\
Fayda görmeme & 17 & 1.7 \\
\hline Uygulama nedenleri* & & \\
\hline Medikal tedavinin pahalı olmas1 & 937 & 94.8 \\
Medikal tedavinin başarısı olması & 858 & 86.8 \\
\hline
\end{tabular}


Tablo 1. (Devam) 3-6 yaş grubu çocuğa sahip annelerin TAT uygulama özellikleri $(\mathrm{n}=988)$

\begin{tabular}{lcc}
\hline TAT & n & \% \\
\hline Uygulama nedenleri* & & \\
\hline Medikal tedavinin yan etkilerinden korkma & 741 & 75.0 \\
Medikal tedavinin yetersiz olması & 727 & 73.6 \\
TAT yöntemlerine kolay ulaşabilme & 577 & 58.4 \\
\hline Uygulanan durumlar/ hastalıklar* & & \\
\hline Öksürük & 602 & 60.9 \\
Grip & 526 & 53.2 \\
Bağışıklığın güçlendirilmesi & 435 & 44.0 \\
Ateş & 420 & 42.5 \\
Konstipasyon & 389 & 39.4 \\
Diyare & 358 & 36.2 \\
ÜSYE & 346 & 35.0 \\
Gaz sancısı & 328 & 33.2 \\
Anemi & 322 & 32.6 \\
Sarıllik & 214 & 21.7 \\
Pişik & 205 & 20.7 \\
Astım & 126 & 12.8 \\
Burkulma/İncinme & 122 & 12.3 \\
İdrar yolu enfeksiyonu & 83 & 8.4 \\
Göbeğin düşmemesi & 45 & 4.6 \\
Siğil & 41 & 4.1 \\
\hline *Birden fazla yantt verilmiştir. & &
\end{tabular}

Annelerin TAT uygulama yöntemleri Tablo 2'de verilmiştir.

Çalışmadaki annelerin 25-35 yaş grubunda olanların \%84.7'sinin, lise mezunu olanların $\% 86.2$ 'sinin, geniş aile yapısında olanların \%86.5'inin, geliri giderinden düşük olanların $\%$ 83.3'ünün ve geliri giderine eşit olanların $\% 83.2$ 'sinin TAT uyguladıkları saptanmıştır. Araştırmadaki annelerin yaş, eğitim durumu, aile tipi, ve gelir düzeylerine göre TAT uygulama durumları arasındaki farkın istatistiksel olarak anlamlı olmadı ̆̆ belirlenmiştir (sırasıyla; $\mathrm{p}=0.14$; $\mathrm{p}=0.43 ; \mathrm{p}=0.38 ; \mathrm{p}=0.99$; Tablo 3).

\section{Tartışma}

3-6 yaş grubunda çocuğu olan annelerin TAT uygulamalarını ve annelerin tanımlayıcı özelliklerine odaklanarak belirlemek amaciyla yapılan bu çalışmada annelerin \%83.2'sinin çocuğunda TAT uyguladığı belirlenmiştir (Tablo 1). TAT uygulamaları, özel bakım gereksinimi olan ve kronik hastalığa sahip çocuklarda daha fazla kullanılmaktadır (Çarman ve ark., 2018). Pediatrik kanserli hastalarda TAT kullanım sıklığ literatürde farkl11ık göstermekte \%31-84 arasında değiştiği belirtilmektedir (Ladas ve ark., 2014; Martinez ve ark., 2016). Cocuklarda TAT uygulamaları ile ilgili yapılan çalışmalar çoğunlukla kronik hastalığı olan çocuklarda gerçekleştirilmiş (Aydın ve ark., 2015; Akçay ve Yıldırımlar, 2017; Bulut Kobya ve Bektaş, 2019), kronik hastalığı olmayan çocuklarda TAT uygulamalarını araştıran çalışmaların yetersiz olduğu görülmüştür (Tuncel ve ark., 2014). Bulut Kobya ve Bektaş'ın (2019) kemoterapi alan çocukların ailelerinin \%98.5'inin, Aydın ve ark. (2015) tarafindan yapılan çalışmada üst solunum yolu enfeksiyonu tanısı konan çocukların ailelerinin tamamının (\%100.0) çocuklarına TAT uyguladıkları, Tuncel ve ark. (2014) tarafindan yapılan çalışmada kronik hastalığ 1 olmayan çocuklarda TAT kullanım oranının $\% 83.0$ olduğu belirlenmiştir. $\mathrm{Bu}$ araştırmanın bulguları Tuncel ve ark.'ın (2014) çalışmasına benzer şekilde, annelerin TAT uygulama oranının yüksek olduğunu göstermektedir. $\mathrm{Bu}$ doğrultuda, TAT uygulamaları konusunda pediatri hemşireleri, annelere rutin olarak TAT uygulamalarını sormalı, kullanım nedenlerini ve beklenen sonuçları tartışmalıdır. Hemşireler annelerle bu tür tartışma yoluyla onların tercihlerine yardımcı olabilirler. Ayrıca çalışmadaki annelere "Hangi TAT yöntemlerini kullanıyorsunuz?" sorusuna annelerin hepsinin yanıt verdiğinin gözlenmesi TAT kullanımının belirtilenden daha yüksek olabileceğini göstermektedir.

Tablo 2. 3-6 yaş grubu çocuğa sahip annelerin durum/ hastalığa göre TAT yöntemleri

\begin{tabular}{llcc}
\hline Durum/Hastalık & TAT yöntemleri & n & \% \\
\hline \multirow{3}{*}{ Öksürük* } & Bal yedirme & 364 & 36.8 \\
& Pekmez yedirme & 180 & 18.0 \\
& Bitki çayı içirme & 75 & 7.6 \\
\hline Grip & Bitki çayı içirme & 276 & 27.9 \\
\hline & Bıldırcın yumurtası & 364 & 36.8 \\
& yedirme & & \\
& Balık yağı içirme & 275 & 27.8 \\
& Arı sütü yedirme & 122 & 12.3 \\
& Bal yedirme & 113 & 11.4 \\
& Pekmez yedirme & 100 & 10.1 \\
Bağışıklığın & Bitki çayı içirme & 91 & 9.2 \\
güçlendirilmesi* & Kurşun dökme & 55 & 5.6 \\
& Kundak yapma & 48 & 4.9 \\
& Nazar boncuğu & 37 & 3.7 \\
& Kirklama/tuzlama & 36 & 3.6 \\
& Hindistan cevizi & 33 & 3.3 \\
& yedirme & & \\
\hline \multirow{2}{*}{ Ateş* } & Sirke sürme & 369 & 37.3 \\
\hline Konstipasyon* & Bitki çayı içirme & 70 & 7.1 \\
\hline \multirow{3}{*}{ Diyare* } & Zeytinyağı içirme & 314 & 31.8 \\
\hline \multirow{2}{*}{ Üst Solunum Yolu } & Kola aspirin & 181 & 18.3 \\
Enfeksiyonu* & Kahve/limon & 161 & 16.3 \\
& yedirme & & \\
\hline & Balık yağı içirme & 132 & 13.4 \\
& Bıldırcın yumurtası & 102 & 10.3 \\
& yedirme & & \\
& Bitki çayı içirme & 89 & 9.0 \\
\hline & & & \\
& &
\end{tabular}


Tablo 2. (Devam) 3-6 yaş grubu çocuğa sahip annelerin durum/ hastalığa göre TAT yöntemleri

\begin{tabular}{|c|c|c|c|}
\hline Durum/Hastalık & TAT yöntemleri & n & $\%$ \\
\hline \multirow{4}{*}{ Gaz sancis1* } & $\begin{array}{l}\text { Hindistan cevizi } \\
\text { yedirme }\end{array}$ & 311 & 31.4 \\
\hline & Masaj yapma & 275 & 27.8 \\
\hline & Zeytinyağ 1 içirme & 107 & 10.8 \\
\hline & Kundak & 44 & 4.5 \\
\hline Anemi & Pekmez yedirme & 343 & 34.7 \\
\hline \multirow{6}{*}{ Sarılık* } & Sarı giydirme & 210 & 21.3 \\
\hline & Altın takma & 96 & 9.7 \\
\hline & Kirklama/tuzlama & 61 & 6.2 \\
\hline & Nazar boncuğu & 59 & 6.0 \\
\hline & Ekmek koyma & 42 & 4.3 \\
\hline & Kaş çizme & 35 & 3.5 \\
\hline Pişik & Toprağa yatırma & 94 & 9.5 \\
\hline \multirow{3}{*}{ Astım* } & Bal yedirme & 67 & 6.8 \\
\hline & Arı sütü yedirme & 51 & 5.2 \\
\hline & Pekmez yedirme & 45 & 4.6 \\
\hline \multirow{3}{*}{ Burkulma/İncinme* } & Masaj yapma & 110 & 11.1 \\
\hline & Ekmek koyma & 79 & 8.0 \\
\hline & Yemeni bağlama & 47 & 4.8 \\
\hline Siğil & Nazar boncuğu & 21 & 2.1 \\
\hline
\end{tabular}

$\mathrm{Bu}$ çalışmada annelerin çoğunluğunun TAT uygulamalarından "kısmen fayda gördüğünü" (\%61.5; $\mathrm{n}=608)$ ifade ettikleri saptanmıştır (Tablo
1). Çocuklarda karaciğer ve böbrek fonksiyonları iyi gelişmediğinden TAT uygulamalarının yan etkileri olabilmekte ve tıbbi tedaviyi birakma ya da geciktirme gibi yan etkileri de görülebilmektedir (Bulut Kobya ve Bektaş, 2019; McClafferty ve ark., 2017). Akçay ve Yıldırımlar'ın (2017) yaptığı çalışmada ailelerin TAT kullanırken yarısından fazlasının çocuğunda herhangi bir yarar, tamamına yakını herhangi bir zarar da gözlemlemediğini belirtmiştir. Araz ve Bülbül'ün (2011) yaptığ1 çalışmada, ailelerin \%57.7'sinin kullandıkları yöntemi "biraz" yararlı buldukları belirlenmiștir. Bu çalışmada annelerin TAT uygulamasından "kısmen fayda gördüklerini" ifade edenlerin oranının yüksek olması, Araz ve Bülbül'ün (2011) yaptı̆̆ çalışma sonuçları ile paraleldir. Bu çalışma sonuçlarına göre çocuk hemşireleri, TAT uygulamalarının dozajları, etkinliği, toksisiteleri, olası ilaç etkileşimleri ve yan etkileri konusunda bilgili olmalı, annelerin TAT uygulamalarını rutin olarak sormalı ve kullanım nedenleri ile beklenen sonuçları tartışmalıdırlar. Böylece pediatri hemşirelerinin annelerin hatalı uygulamalarının önlenmesine katkıda bulunabileceği düşünülmektedir.

Tablo 3. Annelerin tanımlayıcı özelliklerine göre TAT yöntemlerini uygulama durumlarının karşılaştırılması

\begin{tabular}{|c|c|c|c|c|c|c|}
\hline \multirow{2}{*}{\multicolumn{2}{|c|}{ Tanımlayıcı Özellikler }} & & \multicolumn{2}{|c|}{ TAT Uygulama Durumları } & \multirow[t]{2}{*}{ Toplam } & \multirow{2}{*}{ İstatistiksel Analiz } \\
\hline & & & Uygulayan & Uygulamayan & & \\
\hline \multirow{8}{*}{ 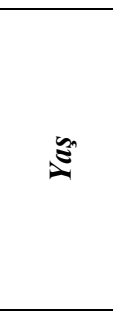 } & \multirow{2}{*}{$<25$} & $\mathrm{n}$ & 31 & 8 & 39 & \multirow{8}{*}{$\begin{array}{l}\mathrm{F}=2.181 \\
\mathrm{p}=0.14^{*}\end{array}$} \\
\hline & & $\%$ & 79.4 & 20.6 & 100.0 & \\
\hline & \multirow{2}{*}{$25-35$} & $\mathrm{n}$ & 616 & 111 & 727 & \\
\hline & & $\%$ & 84.7 & 15.3 & 100.0 & \\
\hline & \multirow{2}{*}{$36-45$} & $\mathrm{n}$ & 168 & 45 & 213 & \\
\hline & & $\%$ & 78.8 & 21.2 & 100.0 & \\
\hline & \multirow{2}{*}{$>45$} & $\mathrm{n}$ & 7 & 2 & 9 & \\
\hline & & $\%$ & 77.7 & 22.3 & 100.0 & \\
\hline \multirow{8}{*}{ 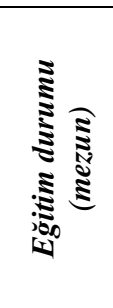 } & \multirow{2}{*}{ Okur-yazar } & $\mathrm{n}$ & 17 & 3 & 20 & \multirow{8}{*}{$\begin{array}{l}\mathrm{F}=0.621 \\
\mathrm{p}=0.43^{*}\end{array}$} \\
\hline & & $\%$ & 85.0 & 15.0 & 100.0 & \\
\hline & \multirow{2}{*}{ İlköğretim } & $\mathrm{n}$ & 347 & 81 & 428 & \\
\hline & & $\%$ & 81.0 & 19.0 & 100.0 & \\
\hline & \multirow{2}{*}{ Lise } & $\mathrm{n}$ & 269 & 43 & 312 & \\
\hline & & $\%$ & 86.2 & 13.8 & 100.0 & \\
\hline & \multirow{2}{*}{ Üniversite ve üzeri } & $\mathrm{n}$ & 189 & 39 & 228 & \\
\hline & & $\%$ & 82.8 & 17.2 & 100.0 & \\
\hline \multirow{6}{*}{ 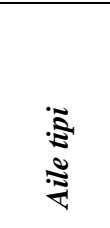 } & \multirow{2}{*}{ Çekirdek } & $\mathrm{n}$ & 646 & 137 & 783 & \multirow{6}{*}{$\begin{array}{l}\mathrm{F}=0.762 \\
\mathrm{p}=0.38 *\end{array}$} \\
\hline & & $\%$ & 82.5 & 17.5 & 100.0 & \\
\hline & \multirow{2}{*}{ Geniş } & $\mathrm{n}$ & 148 & 23 & 171 & \\
\hline & & $\%$ & 86.5 & 13.5 & 100.0 & \\
\hline & \multirow{2}{*}{ Parçalanmış } & $\mathrm{n}$ & 28 & 6 & 34 & \\
\hline & & $\%$ & 82.3 & 17.7 & 100.0 & \\
\hline \multirow{6}{*}{ 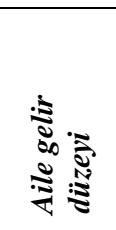 } & \multirow{2}{*}{ Geliri giderinden düşük } & $\mathrm{n}$ & 140 & 28 & 168 & \multirow{6}{*}{$\mathrm{F}=0,15 \mathrm{p}=0.99 *$} \\
\hline & & $\%$ & 83.3 & 16.7 & 100.0 & \\
\hline & \multirow{2}{*}{ Geliri giderine eşit } & $\mathrm{n}$ & 566 & 114 & 680 & \\
\hline & & $\%$ & 83.2 & 16.8 & 100.0 & \\
\hline & \multirow{2}{*}{ Geliri giderinden fazla } & $\mathrm{n}$ & 116 & 24 & 140 & \\
\hline & & $\%$ & 82.9 & 17.1 & 100.0 & \\
\hline
\end{tabular}


$\mathrm{Bu}$ çalışmada annelerin TAT uygulama sebepleri içerisinde ilk üç sırada medikal tedavinin pahalı olması, başarısız olması ve yan etkilerinden korkma bulunmaktadır (Tablo 1). TAT uygulamalarını etkileyen faktörlerin temelinde; tıbbi tedavilerin yan etkilerini azaltma, sağlıklı yaşama isteği, bağışıklık sistemini güçlendirme, tıbbi tedaviden duyulan rahatsızlık, tıbbi tedavinin pahalı olması, arkadaş, ailelerinden gelen TAT uygulamaları ile ilgili olumlu geri bildirimler bulunmaktadır (Ladas ve ark., 2014; Paknejad ve ark., 2019). Yapılan bir çalışmada ailelerin çocukları için TAT uygulama nedenleri arasında, tıbbi yöntemlerin yanında yarar elde etme, çocuğunun bu yöntemleri daha kolay kabullenmesi ve tıbbi tedavilerin yan etkilerinin daha çok olmasını üst sırada belirtmişlerdir (Akçay ve Yildırımlar, 2017). Bulut Kobya ve Bektaş (2019) çalışmalarında, kanser tanısı alan çocukların aileleri, çocuklarına TAT uygulama nedeni olarak üst sıralarda vücut direncini artırmak olduğunu belirtmiştir. Bu çalışmada annelerin TAT uygulama sebepleri literatür ile benzerlik göstermektedir.

3-6 yaş grubunda çocuğu olan annelerin TAT uygulamalarının belirlendiği bu çalışmada, annelerin TAT uygulama tercihleri arasinda ilk sırada öksürük yer almaktadır ve annelerin öksürük durumunda TAT uygulamaları açısından en fazla bal yedirdikleri onu pekmez yedirme ve bitki çayı içirmenin izlediği saptanmıştır (Tablo 2). Yapılan çalışmalarda (Aydın ve ark., 2015; Topaloğlu ve ark., 2013; Tuncel ve ark., 2014); astım, KOAH, bronşit, alerjik rinit, öksürük gibi birçok solunum sistemi hastalığında TAT kullanımının yaygın olduğu belirtilmektedir. Öksürügü geçirmek için çocuğun göğsüne yağ sürme ya da gazete kağıdı koyma, çocuğu terletme, sırtına yün ya da sıcak havlu yerleştirme, balı turp suyu ile karıştırıp içirme, çocuğa karabiberli çay ya da süt, kekik, nane, şerbet, keten tohumu, limon, pekmez ve zeytinyağ 1 içirme gibi alternatif tıp yöntemleri uygulanmaktadır (Aydın ve ark., 2015; Topaloğlu ve ark., 2013; Tuncel ve ark., 2014). Oduwole ve ark.'nn (2018) çalışmalarında çocuklarda öksürük semptomlarını geçirmede bal kullanımının kanıtlanmış kesin bir kanıtı olmamakla birlikte hiçbir tedavi uygulamamasından daha iyi bir seçenek olduğu bildirilmiştir. $\mathrm{Bu}$ çalışmada annelerin öksürük durumunda TAT yöntemlerinden bal yedirmesi, Aydın ve ark. (2015), Büyük ve ark. (2014) ile Topaloğlu ve ark. (2013) tarafından yapılan çalışma sonuçları ile benzerlik göstermektedir.

Bu çalışmada annelerin yaşı, eğitim durumu, aile tipi ve sosyo ekonomik durumuna göre çocuğu için
TAT uygulama durumları arasındaki farkın istatistiksel olarak anlamlı olmadığı belirlenmiştir ( $>0.05$; Tablo 3). Literatürde ailelerin yaşı, eğitim durumu, meslekleri, yaşadıkları yer, aile tipi, algılanan gelir ve sosyal güvence durumlarının TAT uygulamalarını etkilediğini bildiren çalışmalar olduğu gibi (Çarman ve ark., 2018; Taşar ve ark., 2011; Topaloğlu ve ark., 2013), ailelerin sosyodemografik ve kültürel özelliklerinin TAT uygulamalarını etkilemediğini bildiren çalışmalar da (Aydın ve ark., 2015; Bulut Kobya ve Bektaş, 2019) yer almaktadır. Aydın ve ark. (2015) çalışmalarında annelerin eğitim seviyeleri düştükçe alternatif tedavi uygulamalarından faydalanma oranı artsa da aralarında istatiksel yönden bir anlamlıl1k gözlenmemiştir. Topaloğlu ve ark.'in (2013) çalışmalarında ise ailelerin eğitim düzeyi ile çocuklarına TAT uygulama sıklı̆̆ ilişkinin anlamlı olduğu, eğitim düzeyi yükseldikçe TAT uygulamalarının azaldı̆̆ 1 belirtilmiştir. Yine çocuğu için TAT uygulamalarının gelir düzeyi yüksek olanlarda daha s1k olduğunu bildiren çalışmalar bulunduğu gibi gelir düzeyi ile ilişsili olmadığını gösteren çalışmalar da bulunmaktadır (Akçay ve Y1ldırımlar, 2017; Araz ve Bülbül, 2011; Tuncel ve ark., 2014). Bu çalışmada annelerin yaş, eğitim durumu, aile tipi ve sosyo ekonomik durumunun çocuğundaki TAT uygulamalarını etkilemediğinin belirlenmesi, annelerin TAT uygulama sıklığının, annenin yaş, eğitim durumunu, aile tipi ve sosyo ekonomik durumundan bağımsız olduğunu göstermektedir.

\section{Sonuç ve Öneriler}

Sonuç olarak, TAT uygulama oranları, 3-6 yaş grubu çocuğu olan annelerde yüksektir. Araştırmadaki annelerin tamamının çocuğu için TAT yöntemlerinden en az birini kullandiğ 1 belirlenmiş ve annelerin yaş, eğitim durumu, aile tipi ve aile gelir düzeylerinin TAT uygulamalarını etkilemediği görülmüştür. Pediatri hemşirelerinin, TAT uygulamalarının olası riskleri, yararları ve kısıtlamaları hakkında yeterli bilgiye sahip olmaları, bu konuda annelerin bilgilendirilmesi çok önemlidir. Ülke genelinde TAT kullanma yaygınlığının belirlenmesi için araştırmaların çok merkezli gerçekleştirilmesi önerilmektedir.

\section{Araştırmanın Sınırlılıkları}

$\mathrm{Bu}$ çalışma bir ilin Milli Eğitim Müdürlüğüne bağlı tüm anaokullarında bulunan 3-6 yaş grubundaki çocukların annelerine yapıldığından 
sonuçlar genellenemez. Çalışma bulguları katılımcıların beyanına dayanmaktadır.

Araştırmanın Etik Yönü/ Ethics Committee Approval: Araştırmaya başlamadan önce İl Milli Eğitim Müdürlüğü onayı (27.01.2015/43436584) ve Etik Kurul onayı alınmıştır (19.02.2015/E-15-425). Ayrıca araştırmaya dahil edilmesi planlanan annelere araştırmanın amacı ile ilgili bilgi verilerek araştırmaya katılıp katılmama kararı kendilerine bırakılmıştır. Çalışmaya katılan annelerden yazılı onam alınmıştır.

Hakem/Peer-review: D1ş hakem değerlendirmesi.

Yazar Katkısı/Author Contributions: Fikir/kavram: SÖA, ZD; Tasarım: SÖA, ZD; Danışmanlık: SÖA; Veri toplama ve/veya Veri İşleme: SÖA; Analiz ve/veya Yorum: SÖA, ZD; Kaynak Tarama SÖA, ZD, ZA, SS; Makalenin Yazımı: SÖA, ZD, ZA, SS; Eleștirel inceleme: SÖA, ZD, ZA, SS.

Çıkar çatışması/Conflict of interest: Herhangi bir çıkar çatışması bulunmamaktadır.

Finansal Destek/Financial Disclosure: Herhangi bir finansal destek bulunmamaktadır.

\section{Çalışma Literatüre Ne Kattı?}

- TAT uygulama oranlarının kronik hastalığı olmayan/sağlıklı 3-6 yaş grubu çocuğu olan annelerde yüksek olduğu ve annelerin bu yöntemden en az birini uyguladığı belirlenmiş̧ir.

- Annelerin yaşı, eğitim durumu, aile tipi ve aile gelir düzeyleri TAT uygulamalarını etkilememiştir.

- Çocuk hemşirelerinin annelerin uyguladıkları TAT yöntemleri ile ilgili farkındalıklarının artırılması açıssından literatüre katkı sağlayacağ 1 düşünülmektedir.

\section{Kaynaklar}

Aguilar BA. (2017). The efficacy of art therapy in pediatric oncology patients: an integrative literatüre review. Journal of Pediatric Nursing, 36, 173-178.

Akçay D, Yıldırımlar A. (2017). Çocuklarda tamamlayıcı ve alternatif tedavi kullanımı ve ebeveyn bilgilerinin değerlendirilmesi. Journal of the Child, 17(4), 174181.

Anheyer D, Kern C, Dobos G, Cramer H. (2018). "I think you can achieve quite a lot if all of the staff stands behind it" -A qualitative study about the experience, knowledge and application of complementary therapies and integrative medicine in pediatrics. Complementary Therapies in Medicine, 41, 186-191.

Araz N, Bülbül S. (2011). Use of complementary and alternative medicine in a pediatric population in Southern Turkey. Clinical and Investigative Medicine, 34(1), 21-29.
Aydın D, Çiftçi EK., Kahraman S, Şahin N. (2015). Solunum yolu enfeksiyonu geçiren çocuklarda alternative tedavi uygulamaları. Journal of Pediatric Research, 2(4), 212-217.

Bulut Kobya H, Bektaş M. (2019). Kemoterapi alan çocuklarda tamamlayıcı tedavi kullanımı. Geleneksel ve Tamamlayıcı Tip Dergisi, 2(3), 106-117.

Büyük ET, Gürel E, Kalaycı N. (2014). Annelerin öksürügü olan çocuklara yaklaşımları. Gümüşhane Üniversitesi Sağlık Bilimleri Dergisi, 3(4), 10191031.

Ceyhan D, Yiğit Tasya T. (2016). Güncel tamamlayıcı ve alternatif tıbbi tedavilerin sağlık uygulamalarındaki yeri. Düzce Üniversitesi Sağlık Bilimleri Enstitüsü Dergisi, 6(3), 178-189.

Choi E, Jang E, Lee JH. (2019). Pharmacological activities of alisma orientale against nonalcoholic fatty liver disease and metabolic syndrome: Literature Review. Evidence-based Complementary and Alternative Medicine, 2, 1-15.

Çarman KB, Gürlevil SL, Kaplan E, Dinleyici M, Yarar C,Arslantaş D. (2018). The evaluation of use of complementary and alternative medicine practices in the treatment of children with chronic neurological disease. Haydarpasa Numune Medical Journal, 58(3), 117-121.

Ho KY, Lam KKW, Chung JOK, Xia W, Cheung AT, Ho LK. ve ark. (2019). Systematic review of the effectiveness of complementary and alternative medicine on nausea and vomiting in children with cancer: A study protocol. BMJ Open, 9(10), e031834.

Kemper KJ, Vohra S, Walls R. (2018). American Academy of Pediatrics. The use of complementary and alternative medicine in pediatrics. Pediatrics, 122(6), 1374-1386.

Ladas EJ, Rivas S, Ndao D, Damoulakis D, Bao YY, Cheng B. ve ark. (2014). Use of traditional and complementary/alternative medicine (TCAM) in children with cancer in Guatemala. Pediatric Blood \& Cancer, 61(4), 687-692.

Martínez RG, Rodríguez CC, Carrillo Mu, Solis O, González M, Colunga JC. ve ark. (2016). Attitudes and uses of alternative medicine by physicians at a pediatric hospital in Mexico. Advances in Applied Sociology, 6(6), 225-233.

McClafferty H, Vohra S, Bailey M, Brown M, Esparham A, Gerstbacher D. ve ark. (2017). Pediatric integrative medicine. Pediatrics, 140(3), e20171961.

National Center for Complementary and Integrative Health (NCCIH) 2019. Complementary, alternative, or integrative health: what's in a name? U.S. Department of Health and Human Services. Erişim tarihi: $\quad 8 \quad$ Temmuz 2020, https://nccih.nih.gov/health/integrative-health.

Ng JY, Mohiuddin U. (2020). Quality of complementary and alternative medicine recommendations in low back pain guidelines: a systematic review. European Spine Journal, 29(8), 1833-1844. 
Oduwole O, Udoh EE, Oyo-Ita A, Meremikwu MM. (2018). Honey for acute cough in children. Cochrane Database of Systematic Reviews, 4, CD007094.

Paknejad MS, Motaharifard MS, Barimani S, Kabiri P, Karimi M. (2019). Traditional, complementary and alternative medicine in children constipation: a systematic review. DARU Journal of Pharmaceutical Sciences, 27(2), 811-826.

Resmi Gazete (21.10.2014, Say1: 29158) sayılı Geleneksel ve Tamamlayıcı Tip Uygulamaları Yönetmeliği 2014. p.72.

Taşar MA, Potur ED, Kara N, Bostancı İ, Dallar Y. (2011). Düşük gelir düzeyine sahip ailelerin çocuklarına tamamlayıcı veya alternatif tıp uygulamaları: Ankara hastanesi verileri. Türkiye Çocuk Hastalıkları Dergisi, 5(2), 81-88.

Topaloğlu N, Yıldırım Ş, Tekin M, Uludağ A, Özgen K (2013). Türkiye'nin batısında solunum yolu enfeksiyonu geçiren çocuklarda alternatif tedavi uygulamaları. Güncel Pediatri, 11(1), 23-26.

Tuncel T, Şen V, Kelekçi S, Karabel M, Uluca Ü, Karabel D. ve ark. (2014). Kronik hastalığ 1 olmayan çocuklarda tamamlayıcı ve alternatif tıp kullanımı. Türk Pediatri Arşivi, 49, 148-153.

Wopker PM, Schwermer M, Sommer S, Längler A, Fetz K, Ostermann T. ve ark. (2020). Complementary and alternative medicine in the treatment of acute bronchitis in children: A systematic review. Complementary Therapies in Medicine, 49, 102217.

Zhang Z, Hu J. (2016). Recent advances and perspective of studies on phlegm syndrome in chinese medicine. Evidence- Based Complementary and Alternative Medicine, 6463270.

Zuzak TJ, Boňková J, Careddu D, Garami M, Hadjipanayis A, Jazbec J. ve ark. (2013). Use of complementary and alternative medicine by children in Europe: published data and expert perspectives. Complementary Therapies in Medicine, 21(1), 34-47. 